\title{
Measuring the response of human head and neck squamous cell carcinoma to irradiation in a microfluidic model allowing customized therapy
}

\author{
RAMSAH CHEAH $^{1}$, RISHI SRIVASTAVA ${ }^{1}$, NICHOLAS D. STAFFORD ${ }^{1}$, \\ ANDREW W. BEAVIS ${ }^{3,4}$, VICTORIA GREEN ${ }^{2}$ and JOHN GREENMAN ${ }^{2}$ \\ ${ }^{1}$ Hull York Medical School, ${ }^{2}$ School of Life Sciences, ${ }^{3}$ Radiation Physics, Hull and East Yorkshire \\ Hospitals NHS Trust, Faculty of Science and Engineering, University of Hull, Hull, HU6 7RX; \\ ${ }^{4}$ Faculty of Health and Wellbeing, Sheffield Hallam University, Sheffield, S1 1WB, UK
}

Received May 22, 2017; Accepted July 31, 2017

DOI: 10.3892/ijo.2017.4118

\begin{abstract}
Radiotherapy is the standard treatment for head and neck squamous cell carcinoma (HNSCC), however, radioresistance remains a major clinical problem despite significant improvements in treatment protocols. Therapeutic outcome could potentially be improved if a patient's tumour response to irradiation could be predicted ex vivo before clinical application. The present study employed a bespoke microfluidic device to maintain HNSCC tissue whilst subjecting it to external beam irradiation and measured the responses using a panel of cell death and proliferation markers. HNSCC biopsies from five newly-presenting patients [2 lymph node (LN); 3 primary tumour (PT)] were divided into parallel microfluidic devices and replicates of each tumour were subjected to single-dose irradiation $(0,5,10,15$ and $20 \mathrm{~Gy})$. Lactate dehydrogenase (LDH) release was measured and tissue sections were stained for cytokeratin (CK), cleaved-CK18 (cCK18), phosphorylated$\mathrm{H} 2 \mathrm{AX}(\gamma \mathrm{H} 2 \mathrm{AX})$ and $\mathrm{Ki}-67$ by immunohistochemistry. In addition, fragmented DNA was detected using terminal deoxynucleotidyl transferase dUTP nick end labelling (TUNEL). Compared with non-irradiated controls, higher irradiation doses resulted in elevated CK18-labelling index in two lymph nodes [15 Gy; $34.8 \%$ on LN1 and $31.7 \%$ on LN2 $(\mathrm{p}=0.006)]$ and a single laryngeal primary tumour (20 Gy; 31.5\%; $p=0.014)$. Significantly higher levels of DNA fragmentation were also detected in both lymph node samples and one primary tumour but at varying doses of irradiation, i.e., LN1 (20 Gy; 27.6\%; p=0.047), LN2 (15 Gy; $15.3 \% ; \mathrm{p}=0.038)$ and PT3 (10 Gy; 35.2\%; $\mathrm{p}=0.01)$. The
\end{abstract}

Correspondence to: Professor John Greenman, School of Life Sciences, University of Hull, Cottingham Road, Hull, HU6 7RX, UK E-mail: j.greenman@hull.ac.uk

Key words: microfluidic, irradiation, head and neck squamous cell carcinoma, cytokeratin 18 $\gamma \mathrm{H} 2 \mathrm{AX}$ expression was raised but not significantly in the majority of samples. The percentage of Ki-67 positive nuclei reduced dose-dependently following irradiation. In contrast no significant difference in $\mathrm{LDH}$ release was observed between irradiated groups and controls. There is clear interand intra-patient variability in response to irradiation when measuring a variety of parameters, which offers the potential for the approach to provide clinically valuable information.

\section{Introduction}

World-wide head and neck cancer accounts for $\sim 550,000$ new cases annually with $\sim 290,000$ deaths (1). Over the past five decades, a considerable amount of effort has been made to improve the treatment of patients with head and neck squamous cell carcinoma (HNSCC), be it surgery (2), chemotherapy (3), radiotherapy (4), non-surgical checkpoint-inhibition immunotherapy $(5,6)$ or a combination of these $(7)$. Radiotherapy is the primary treatment for early-stage laryngeal cancer (T1 and T2) and is commonly used in conjunction with chemotherapy in T3 laryngeal and oropharyngeal squamous cell carcinoma patients. However, despite the improvements in treatment modalities, the overall 5-year survival rate for patients with head and neck cancer remains low, achieving only $66 \%$ for oral cavity cancers and $63 \%$ for cancers of the pharynx and larynx (8), which is thought to be largely due to the recurrence of the primary tumour as well as intrinsic tumour radioresistance (9-11). Still, what is lacking is a comprehensive understanding of the biological mechanisms of radiotherapy sensitivity, resistance and associated biomarkers. Numerous studies have focused on the identification of predictive biomarkers for radioresistance by studying biopsies removed from treated patients (12-16). In contrast, only a few studies have taken pieces of the actual patient tumour and subjected them to in vitro irradiation with the aim of predicting patient specific tumour sensitivity $(17,18)$, due to the inability to maintain the tumour tissue ex vivo. The evaluation of tumour responses to irradiation ex vivo prior to commencement of the therapeutic intervention, would mean that treatment regimens could be designed on a rational rather than an empirical basis, 
leading to improved quality of life with less side-effects and associated morbidity.

Microfluidic devices provide a platform on which a biomimetic microenvironment for human tissues can be maintained, allowing the culture of biopsies under pseudo in vivo conditions (19). These are simple, reproducible, and highly versatile systems for tissue culture with the preservation of 3-dimensional architecture (20). Microfluidic-based tissue culture mimics the systems of the human body with continuous perfusion, permitting the constant supply of nutrients to, and removal of waste from, multiple pieces of the same patient tissue in parallel (21).

Microfluidic culture of head and neck tumour tissue has been demonstrated previously by colleagues, in which the viability of the cultured tissues was confirmed by the relatively low release of cytosolic enzymes (LDH and cytochrome $c$ ) and high release of proliferation markers (metabolised tetrazolium salts) $(18,22-24)$. A report by Carr et al (18) is the only study so far investigating the response of HNSCC to on-chip X-ray irradiation and showed that administration of fractionated irradiation doses (5x2 Gy over a 5-day period) demonstrated an enhanced level of apoptotic cell death compared to non-irradiated control tissue based on the increased expression of caspase-cleaved cytokeratin 18 (cCK18); also the study showed increased LDH release following high doses of irradiation.

DNA repair pathways remove radiation-induced DNA lesions and protect tumour cells from death. The evidence for the radio-protective effect of cellular DNA repair has been confirmed in cellular, animal and human studies (25-27); individuals with defects in DNA repair pathways often display hypersensitivity to radiation $(28,29)$. Building on the results of previous studies, the present study aimed to determine the effects of single-dose external beam irradiation on microfluidic-perfused HNSCC biopsies using an extended panel of biological markers and expression profiles: caspase-dependent apoptosis (cCK18), caspase-independent necrotic cell death (LDH), DNA damage repair (phosphorylated H2AX), DNA fragmentation (TUNEL) and proliferative status (Ki-67). Ultimately it is hoped that these data could be used to customise patient treatment on a rational basis.

\section{Materials and methods}

HNSCC tissue collection. Samples of HNSCC primary or metastatic node tissue were obtained from 5 patients undergoing resection surgery at Castle Hill Hospital (Hull, UK) with no history of previous treatment (Table I). The project had approval from the Local Research Ethics Committee (LREC-10/H1304/6) and Hull and East Yorkshire NHS Trust R\&D (R0987), and all patients provided written, informed consent. Tissue samples were transported to the laboratory in complete Dulbecco's modified Eagle's medium [DMEM; supplemented with $10 \%$ (v/v) foetal bovine serum (FBS); Biosera, East Sussex, UK), $100 \mathrm{U} / \mathrm{ml}$ penicillin, $100 \mu \mathrm{g} / \mathrm{ml}$ streptomycin, $2 \mathrm{mM}(\mathrm{v} / \mathrm{v})$ L-glutamine and $2.5 \mu \mathrm{g} / \mathrm{ml}$ fungizone (Thermo Fisher, Paisley, UK)] and snap-frozen in liquid nitrogen before storage at $-80^{\circ} \mathrm{C}$ prior to microfluidic culture.

Incubation of HNSCC tissue in a microfluidic device. The microfluidic devices were manufactured in-house in the
Department of Chemistry (University of Hull) and consisted of two thermally bonded layers of glass with micro-etched channels as described previously [(18,22); Fig. 1A)]. As the etching process occurs both horizontally as well as vertically it creates channels with a trapezoidal cross-section (30).

A piece of HNSCC tissue (5-10 mg) was placed in the central tissue chamber (Fig. 1) and perfused with complete DMEM (supplemented with $30 \mathrm{mM}$ HEPES and $0.1 \mathrm{mM}$ NEAA; all medium and supplements were from PAA, Somerset, UK, unless otherwise stated) using tubing connected to a syringe mounted in a Harvard PhD 2000 syringe pump (Harvard, Kent, UK), delivering medium at a rate of $2 \mu \mathrm{l} / \mathrm{min}$. The microfluidic device was placed in a $37^{\circ} \mathrm{C}$ incubator (Novital, Italy; Fig. 1B) and the effluent was collected at 2-h intervals and overnight before storage for up to 6 days at $4^{\circ} \mathrm{C}$ for analysis of $\mathrm{LDH}$ content.

The fluid flow pattern in the microfluidic device was laminar with a flow velocity of $3.96 \times 10^{-3} \mathrm{~m} / \mathrm{sec}$ and a Reynolds number within the microchannel of 0.386 . Diffusion becomes a crucial transport mechanism between the fluid flow and tissue, thus allowing the tissue to access nutrients and reagents supplied via culture medium as well as disposing of cellular waste. This system mimics the nutrient exchange between capillaries and tissue in vivo. When the culture medium is perfused into the microchannel, the fluid layer near the channel is renewed rapidly while the liquid within the chamber mostly recirculates (31). The nutrients from the channels gradually diffuse into the chamber while the waste products diffuse out from the chamber.

In vitro irradiation of tissue in a microfluidic device. Ten parallel microfluidic devices perfusing HNSCC tissue from the same patient were set up each time and following $24 \mathrm{~h}$ of incubation were subjected to single-dose irradiation in duplicate $(0,5,10,15$ and $20 \mathrm{~Gy})$. Irradiation was applied to the tissue under the guidance of medical radiation physicists, using a 6MV X-ray beam from a Varian Clinical Linear Accelerator. During irradiation, the microfluidic device was housed inside a perspex block which served as a surrogate for the tissue around the tumour (Fig. 1C). At a dose rate of $600 \mathrm{MU} / \mathrm{min}$, computerised tomography planning calculated that each beam delivered $53 \mathrm{MU}$, producing a dose of $1 \mathrm{~Gy}$ to the centre of the tissue at gantry angles of $90^{\circ}$ and $270^{\circ}$ with an $8 \times 8 \mathrm{~cm}$ field. Following a further $24 \mathrm{~h}$ of culture post-irradiation, tissue was embedded in OCT embedding medium (CellPath Ltd., UK) and snap-frozen in liquid nitrogen-cooled 2-methyl-butane (Sigma, UK) prior to cryosectioning for IHC analysis.

Measurement of lactate dehydrogenase ( $L D H)$. The release of LDH was measured using the LDH Cytotoxicity Kit ${ }^{\text {plus }}$ (Roche Diagnostics, Hertfordshire, UK) according to the manufacturer's instructions. Medium alone values were subtracted from experimental readings before normalising by the weight of tissue to give $\mathrm{LDH}$ released $/ \mathrm{mg}$. Values were grouped according to a 4-h interval to give a mean before and after irradiation.

Immunohistochemistry (IHC). Tissue sections $(8 \mu \mathrm{m})$ were cut using a cryotome (Leica CM 1100) and mounted onto StarFrost ${ }^{\circledR}$ glass slides (SLS, Nottingham, UK). IHC staining was carried out as described previously (18). The primary antibodies used 

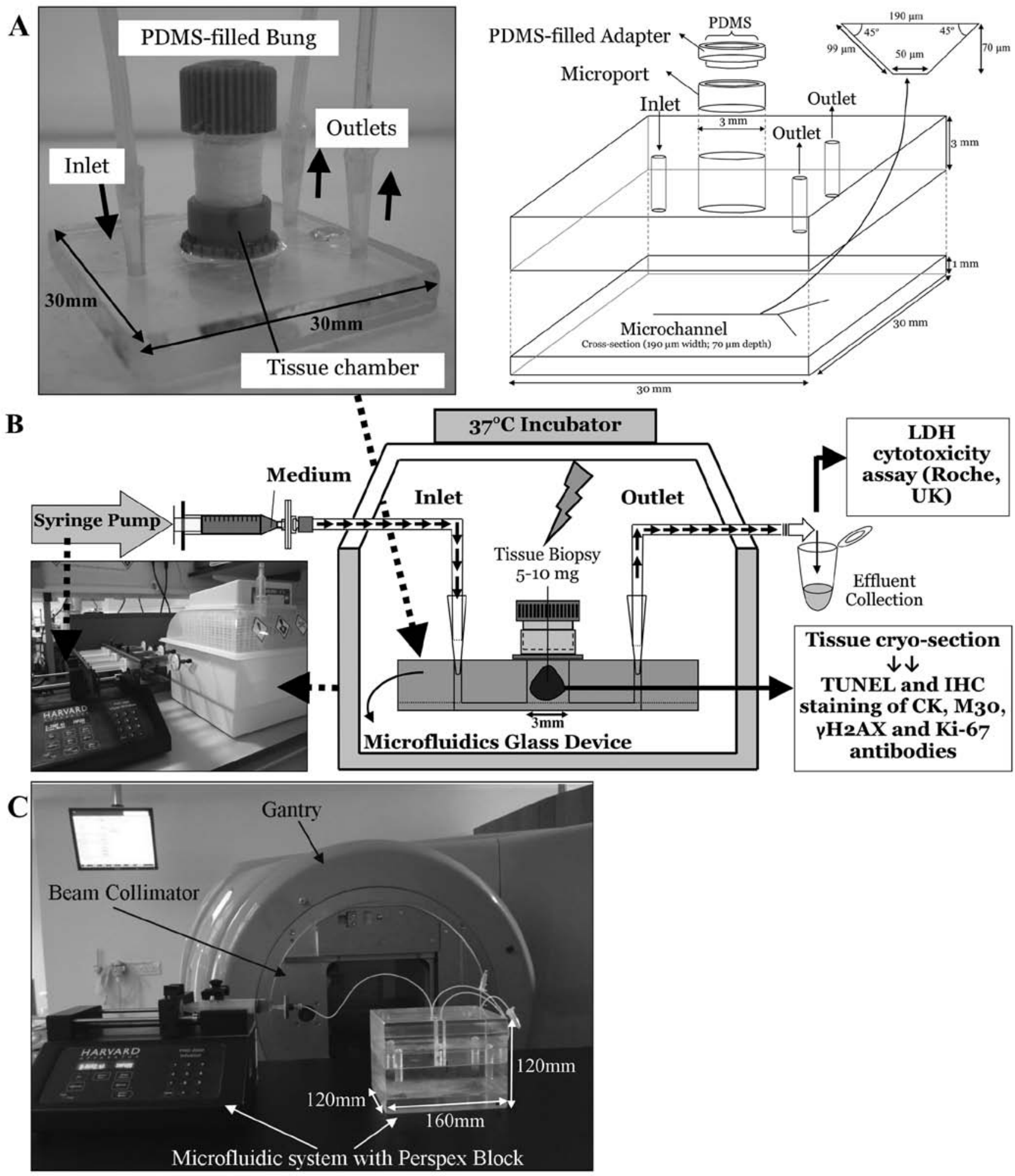

Figure 1. Microfluidic set up for on-chip tissue irradiation. (A) Photograph and schematic diagram showing the assembly of the microfluidic glass device with inlet and outlet tubing and the cross-sectional illustration of microchannel. (B) Schematic diagram of the entire microfluidic culture set up and analyses. The medium-filled syringe was connected to the microfluidic device which was housed in a $37^{\circ} \mathrm{C}$ incubator. (C) Irradiation of HNSCC tissue in the microfluidic device inside a custom made Perspex Block (160 mm width, $120 \mathrm{~mm}$ height, and $120 \mathrm{~mm}$ depth). The sample was irradiated isocentrically using a dose rate of $600 \mathrm{MU} / \mathrm{min}$ using laterally opposing $8 \times 8 \mathrm{~cm}$ fields with gantry angles of $90^{\circ}$ and $270^{\circ}$. Computerised tomography scans of the equipment were used to perform a 3D treatment planning calculation to produce a dose of $1 \mathrm{~Gy}$ at the sample, requiring $53 \mathrm{MU}$ per field.

in the present study were monoclonal primary mouse antihuman antibodies [M30 (cCK18; Peviva, Tewkesbury, UK), CK (Clone MNF116; Dako, Denmark), phosphorylated H2AX (Clone 2F3; $\gamma \mathrm{H} 2 \mathrm{AX}$; BioLegend, UK) and Ki-67; (Clone
MIB-1; Dako)] at a 1:100 dilution for $1 \mathrm{~h}$ at room temperature. Matched isotype control antibodies at the same concentration provided a non-specific binding control. Antibody binding was detected with biotinylated horse anti-mouse secondary 
Table I. Clinicopathological details of five HNSCC patients, clinical treatment received and outcome.

\begin{tabular}{|c|c|c|c|c|c|}
\hline Sample & Subsite & Stage & Age; gender & $\begin{array}{l}\text { Therapy received } \\
\text { and date }\end{array}$ & $\begin{array}{l}\text { Treatment outcome } \\
\text { (updated June 2016) }\end{array}$ \\
\hline LN 1 & $\begin{array}{l}\text { Unknown } \\
\text { primary }\end{array}$ & TxN2aM0 & $61 ; \mathrm{M}$ & Surgery and CRT & $\begin{array}{l}\text { No local or } \\
\text { regional recurrence }\end{array}$ \\
\hline LN 2 & $\begin{array}{l}\text { Laryngeal } \\
\text { primary }\end{array}$ & $\mathrm{T} 4 \mathrm{~N} 2 \mathrm{bM} 0$ & $58 ; \mathrm{M}$ & Surgery and CRT & No information \\
\hline PT 1 & $\begin{array}{l}\text { Oral cavity floor } \\
\text { of mouth I }\end{array}$ & T3N0M0 & $49 ; \mathrm{M}$ & Surgery & $\begin{array}{l}\text { Passed away due to } \\
\text { alcoholic liver disease }\end{array}$ \\
\hline PT 2 & $\begin{array}{l}\text { Oral cavity floor } \\
\text { of mouth II }\end{array}$ & T2N0 & $64 ; M$ & Surgery & No evidence of recurrence \\
\hline PT 3 & $\begin{array}{l}\text { Laryngeal } \\
\text { supraglottis }\end{array}$ & T2NOMO & $68 ; \mathrm{F}$ & RT & $\begin{array}{l}\text { No evidence of loco-regional } \\
\text { recurrence }\end{array}$ \\
\hline
\end{tabular}

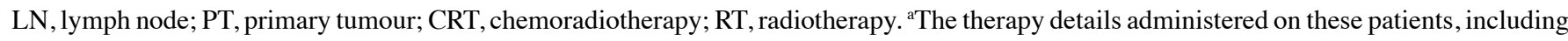
the doses and the chemotherapy drugs, were not available.

antibody and an avidin/biotin system linked to horse peroxidase (Vector Laboratories Ltd., Peterborough, UK), and subsequent reaction with 3, 3'-diaminobenzidine (DAB; Sigma). Sections were counterstained with Harris haematoxylin (Sigma), dehydrated through graded ethanols (70,90 and 100\%), and three changes of Histoclear, before mounting with Histomount (National Diagnostics, Hessle, UK).

Terminal deoxynucleotidyl transferase dUTP nick end labelling (TUNEL). To detect DNA fragmentation, $8 \mu \mathrm{m}$ tissue sections were fixed in $4 \%(\mathrm{w} / \mathrm{v})$ paraformaldehyde for $20 \mathrm{~min}$ before being washed with phosphate-buffered saline (PBS; pH 7.4) for $30 \mathrm{~min}$ (32). The cells were permeabilised $(0.1 \%$ Triton $\mathrm{X}-100$ and $0.1 \%$ sodium citrate), rinsed twice with PBS and incubated with terminal deoxynucleotidyl transferase (TdT) and TUNEL label reagent containing fluorescent dUTP, according to the manufacturer's instructions (Roche Diagnostics) for an hour in a dark humidified box at $37^{\circ} \mathrm{C}$. The tissue sections were rinsed three times with PBS before being mounted with Vectashield ${ }^{\circledR}$ mounting medium containing 4', 6-diamidino-2-phenylindole (DAPI; Vector Laboratories Ltd). Additional tissue sections were subjected to 3,000 U/1 DNase (Roche Diagnostics) treatment prior to TdT incubation to serve as a positive control while sections that were not exposed to TdT enzyme after DNase treatment served as a negative control.

Quantification and statistical analysis. A tiled image of the whole tumour section was constructed under x100 magnification and positive staining for M30 and CK on serial sections was evaluated using Image Pro-premier software (Digital Imaging Systems; v9; Fig. 2A). The labelling index of cCK18 was determined as the apoptotic area (M30 positive staining) over the total area of tumour cells (CK positive staining). $\gamma \mathrm{H} 2 \mathrm{AX}$, TUNEL and Ki-67 were evaluated using five randomly selected tumour fields of $x 400$ magnification (Fig. 2B). The number of positively stained nuclei $(\gamma \mathrm{H} 2 \mathrm{AX}$ and $\mathrm{Ki}-67)$ and total nuclei in each field were counted manually using the Point or Multi-point function of ImageJ 1.48v (Java 1.6.0_20 64-bit) and the percentage positivity determined. The area of FITC (green; DNA fragmentation) staining over nuclear DAPI area (blue) on each x400 magnification field was determined and the mean percentage of five fields obtained (Fig. 2B). The mean percentage of duplicate tissues at each irradiation dose were obtained and statistical differences between non-irradiated control and irradiated tissues were determined using one-way ANOVA followed by Tukey's multiple comparison test (IBM SPSS Statistics 22).

\section{Results}

The effect of irradiation on the release of $L D H$. An initial high release of LDH was observed within the first $4 \mathrm{~h}$ after experimental set-up in all tissues (Fig. 3), after which, LDH release decreased and remained low in control tissues. Unexpectedly, the same was true for both the metastatic node and the tumour tissues subjected to irradiation, except for the primary tumours receiving a 5 Gy irradiation. In the 5 Gy treated biopsies, the LDH release increased by $45.5 \%$ during the first 4-h after irradiation and decreased to values similar to that of the control thereafter (Fig. 3B).

The effect of irradiation on $\gamma H 2 A X$ expression. Clear positive brown nuclear staining of $\gamma \mathrm{H} 2 \mathrm{AX}$, but not individual foci, was detected in the HNSCC tissue (Fig. 4A) and irradiation of the two lymph node tissues (LN1 and 2) resulted in up to twice as many positive $\gamma \mathrm{H} 2 \mathrm{AX}$ cells compared with the control at both 10 and $15 \mathrm{~Gy}$, however, the increase was not significant (Fig. 5A). Irradiation of primary tumours 1 and 3 also induced an increase in $\gamma \mathrm{H} 2 \mathrm{AX}$ expression at some irradiation doses, but again, these were not statistically significant. Despite demonstrating almost twice the basal level of $\gamma \mathrm{H} 2 \mathrm{AX}$ expression in the control compared with the other primary tumour tissues, PT2 demonstrated a significant dose-dependent increase in $\gamma \mathrm{H} 2 \mathrm{AX}$ expression following 


\section{A Tiled $\times 100$ images of $\mathrm{CK}$ and M30 staining}

\section{a} CK b Cleaved CK18 (M30)

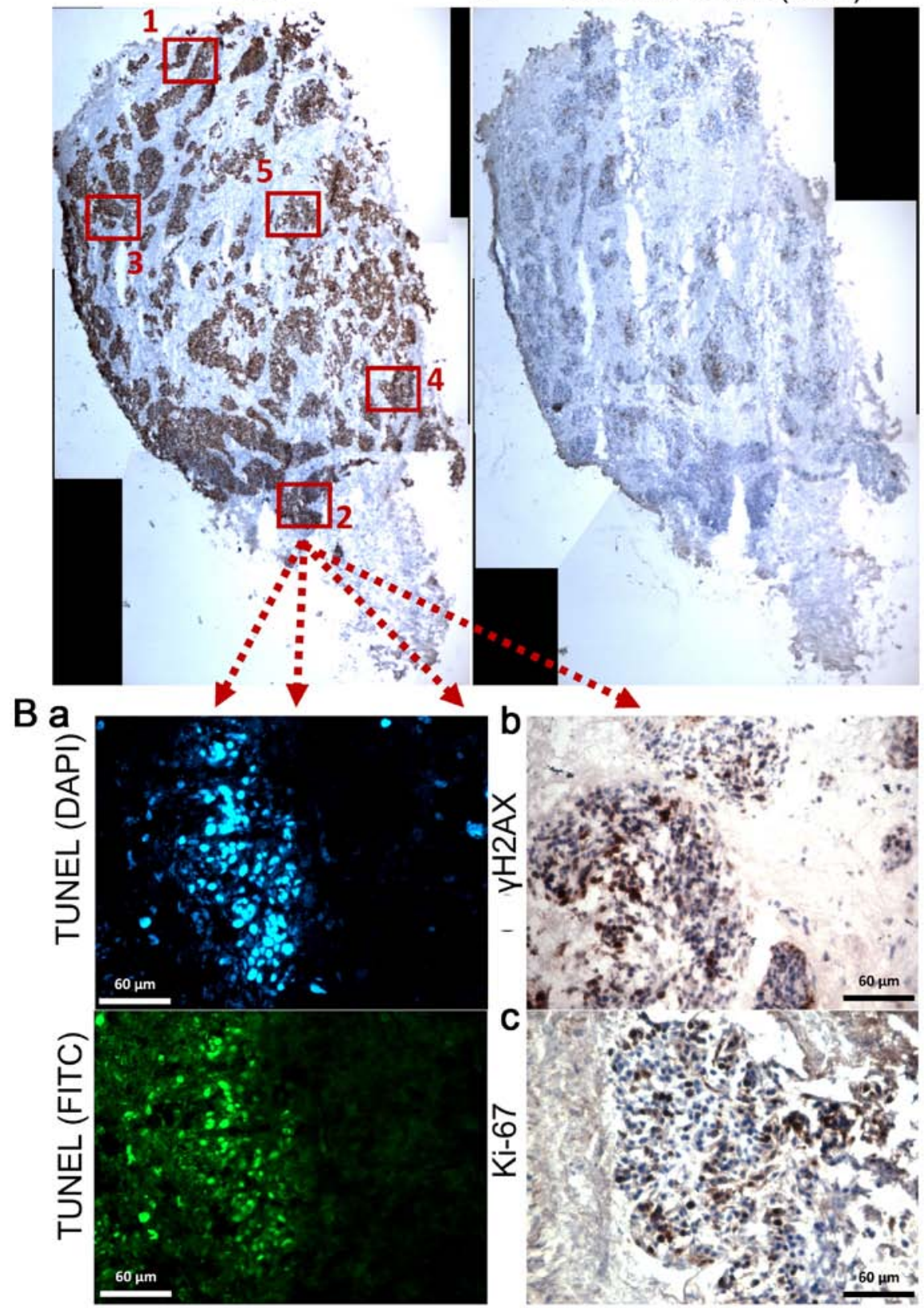

Figure 2. Image analyses on serially sectioned tissue using different markers. (A) IHC staining of (a) CK and (b) cleaved-CK18 (M30) on serially sectioned lymph node tissue containing tumour metastases incubated in the microfluidic device with 5 Gy irradiation treatment (x100 magnification, tiled). (B) Representative image of same lymph node with tumour metastasis visualised at the same area at x400 magnification: (a) TUNEL assay and IHC staining of (b) $\gamma \mathrm{H} 2 \mathrm{AX}$ and (c) Ki-67.

treatment with 10,15 and 20 Gy irradiation $(\mathrm{p}=0.022$ $\mathrm{p}=0.020 ; \mathrm{p}=0.003$, respectively), reaching almost three times the percentage of positive nuclei at the 20 Gy dose $(23.3 \pm 3.0 \%$ control vs. $66.0 \pm 8.0 \% 20 \mathrm{~Gy})$.

The effect of irradiation on CK18-LI. Immunostaining with the M30 antibody demonstrated apoptotic cells with brown cytoplasm (Fig. 4B). A dose of $15 \mathrm{~Gy}$ induced an elevated CK18-LI in LN1 (34.8 $\pm 17.4 \%)$ and LN2 (31.7 $\pm 4.9 \%)$ compared with the corresponding controls $(11.4 \pm 4.0$ and $7.9 \pm 2.1 \%$, respectively; Fig. 5B), but the difference was only significant in LN2 $(\mathrm{p}<0.05)$. The non-irradiated PT3 sample had greater apoptotic cell death $(17.7 \pm 1.3 \%)$ compared with the corresponding controls in other primary tumours $(5.2 \pm 2.2 \% \mathrm{PT}$; $1.9 \pm 0.8 \%$ PT2) and irradiation induced a dose-dependent increase in apoptosis $>10 \mathrm{~Gy}$, however, the difference between irradiated tissue and controls was only significant following 20 Gy irradiation (31.5 $\pm 7.0 \%$ vs. control $17.7 \pm 1.3 \%$; $\mathrm{p}=0.014)$. No significant increases in CK18-LI were observed for PT1 or PT2 following irradiation.

The effect of irradiation on DNA fragmentation. Green fluorescent nuclei demonstrated the presence of incorporated dUTP in apoptotic cells (Fig. 4C). Insufficient tissue meant that 


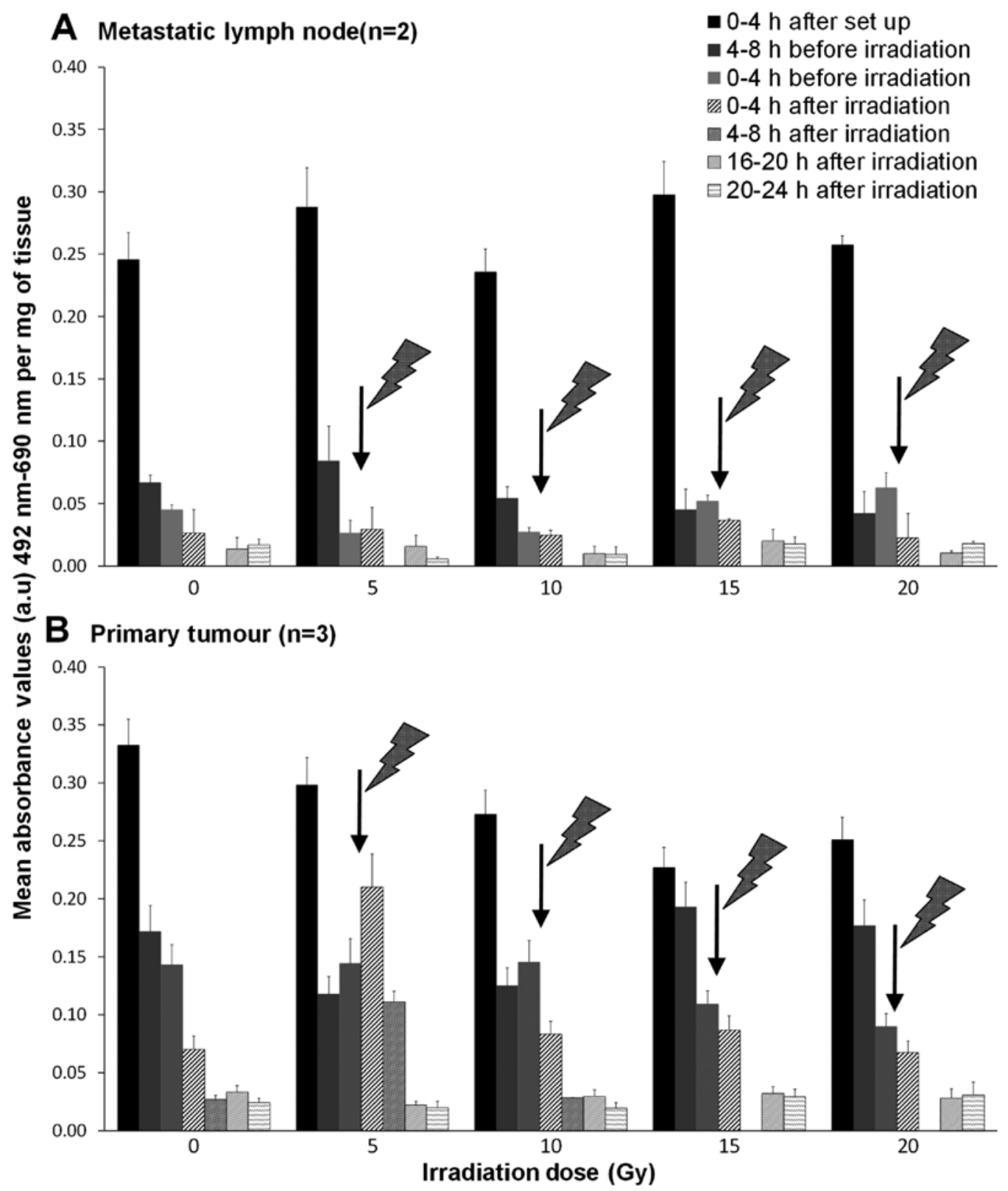

Figure 3. LDH release levels throughout tissue maintenance in microfluidic devices. Mean absorbance values of the tetrazolium product per mg tissue indicating LDH release at 4-h intervals throughout the incubation of tissue in microfluidic devices. (A) LDH released from lymph neck node metastases ( $\mathrm{n}=2$; metastasised from an unknown primary and a laryngeal primary tumour). (B) LDH released from primary tumours ( $\mathrm{n}=3$; two oral cavity floor of mouth tumours and a laryngeal supraglottic tumour). The tissues were subjected to microfluidic culture $(0 \mathrm{~Gy})$ and with four single-dose irradiations $(5,10,15$ and $20 \mathrm{~Gy}$ ). Solid-coloured bars indicate LDH released before irradiation, hatched bars show levels after irradiation. Arrows indicate the time of bilateral X-ray irradiation. Mean \pm SEM.

the evaluation of cells positive for DNA fragmentation in PT1 samples was not possible. The basal fraction of cells demonstrating fragmented DNA was $<10 \%$ in all control tissues investigated, and this increased by $>2$-fold in the four tumours after irradiation, but this increase was not consistent across all doses and only significant following 20 Gy irradiation of LN1 $(27.6 \pm 10.2 \%), 15$ Gy irradiation of LN2 (15.3 $\pm 9.0 \%)$ and $10 \mathrm{~Gy}$ irradiation of PT3 $(35.2 \pm 2.3 \%)$.

The effect of irradiation on proliferation. Positive brown nuclei, representative of Ki-67 positivity, were observed in controls as well as 5 Gy irradiated tissues (Fig. 4D). Although the percentage of cells positive for the proliferation marker
Ki-67 decreased in a dose-dependent manner in both metastatic nodal tissues, the decrease was not significant compared to the controls (Fig. 5D). The degree of proliferation in PT3 decreased by approximately 5 -fold following all irradiation doses except 15 Gy but the decrease was again not significant. In both the floor of mouth tumours (PT1 and PT2), the basal level of proliferation was $<10 \%$ making any effects of irradiation difficult to observe.

Comparison between in vitro results and clinical outcome. In order to determine whether the microfluidic culture of HNSCC tissue and its subsequent irradiation can predict whether a tumour is radioresistant/responsive, the data obtained in vitro 


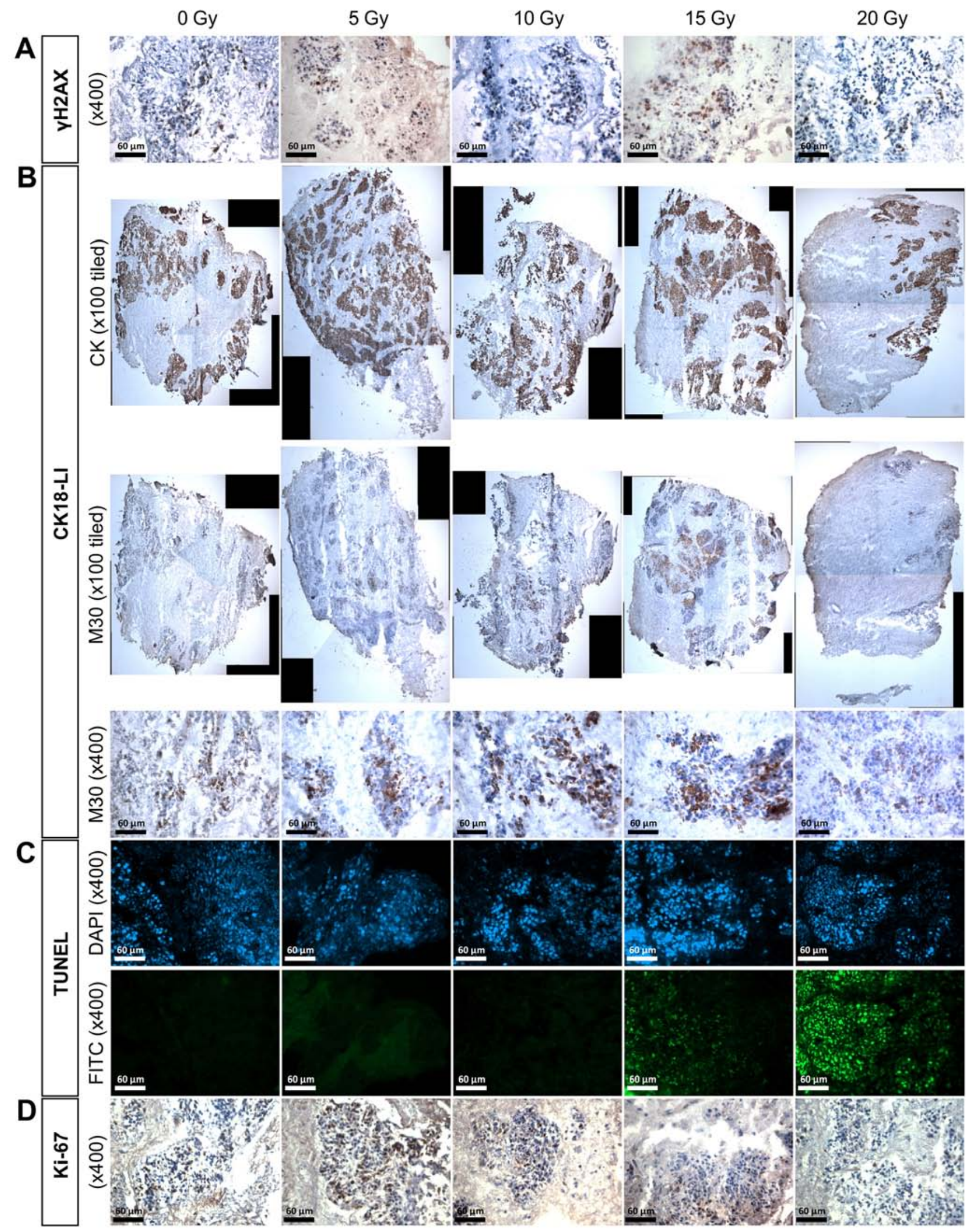

Figure 4. Representative staining images of serially cut tissue sections. Representative images of (A) $\gamma \mathrm{H} 2 \mathrm{AX}$, (B) M30, (C) TUNEL and (D) Ki-67 on lymph neck node metastases following microfluidic culture ( 0 Gy) and four single-dose irradiations (5, 10, 15 and 20 Gy; x100 and x400 magnification).

was compared with the in vivo response to irradiation (Table I). The samples were collected between April and August 2013 with a minimum 2.5-year follow-up. At follow-up, no clinical information was recorded for LN2 and three of the remaining four patients were alive with no evidence of loco-regional recurrence (LN1, PT2 and PT3), however, only two of these 


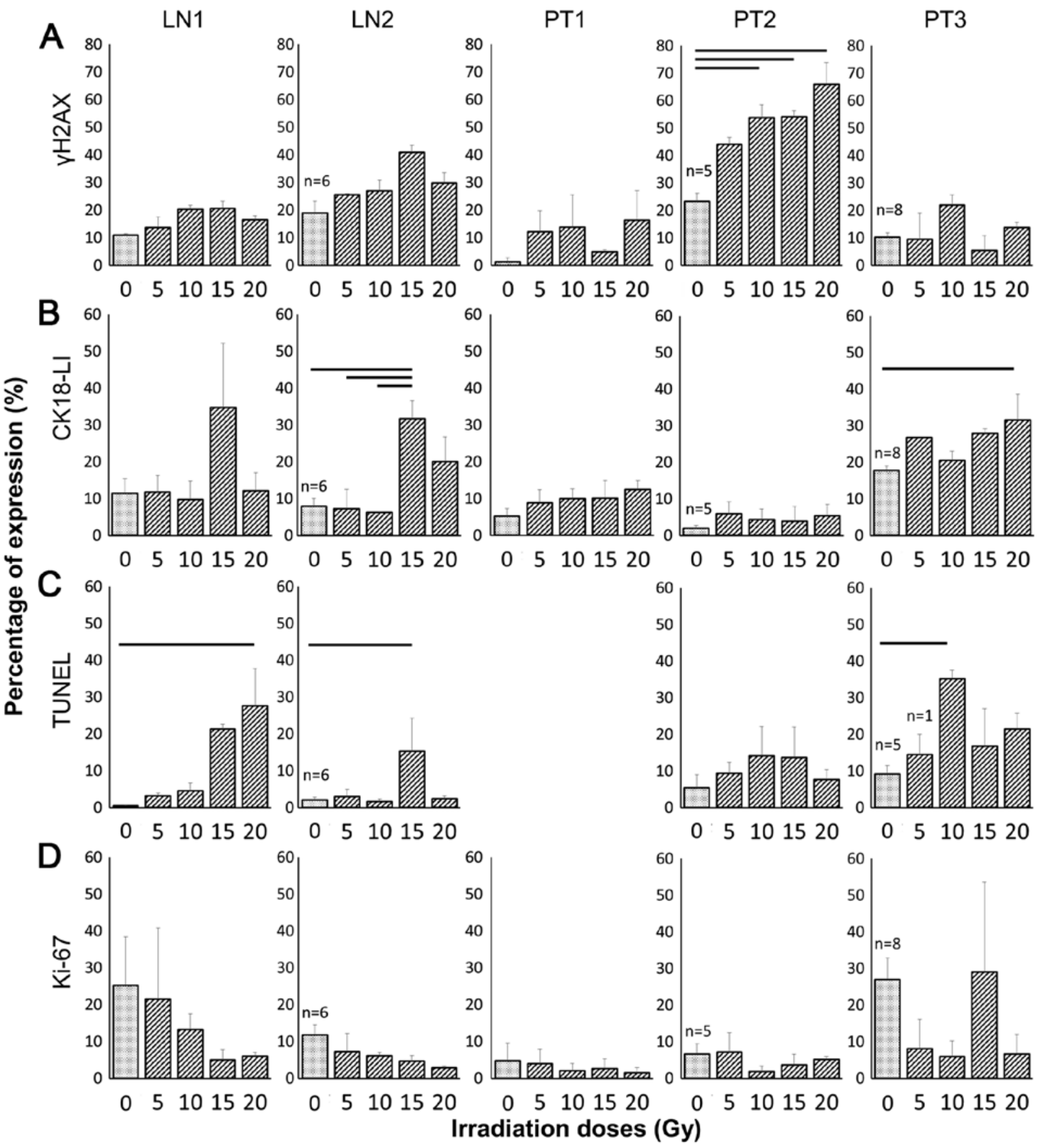

Figure 5. Tumour response of five HNSCC with increasing doses of irradiation. The tumour response was evaluated based on the expression of (A) $\gamma \mathrm{H} 2 \mathrm{AX}$, (B) CK18-LI, (C) TUNEL and (D) Ki-67. Mean \pm SEM. y-axis indicates the percentage of expression. Horizontal lines indicate the significant results between treated samples $(5,10,15$ and $20 \mathrm{~Gy})$ and the non-irradiated control (0 Gy) based on one-way ANOVA with post hoc Tukey's test (p<0.05). At least two tissues were subjected to each treatment $(n=2)$ and the number of repeats, if more than two is shown in parentheses. TUNEL results on PT1 were not possible due to the limitation of tissue.

patients (LN1 and PT3) received any form of radiotherapy. The patient with a laryngeal supraglottic tumour (PT3; T2 tumour) who was treated clinically with radiotherapy had a positive outcome after 3 years with no loco-regional recurrence diagnosed, this is in agreement with the in vitro results which showed a positive response to irradiation in terms of increased cell death (both CK18-LI and TUNEL). LN1 received chemoradiotherapy with a positive outcome which was again reflected in the increased cell death levels (TUNEL) and a trend towards reduced proliferation (Ki-67) observed following on-chip irradiation.

\section{Discussion}

The biological mechanisms present in malignant cells which confer resistance to ionising radiation are largely unknown. The use of immortalised cell lines to investigate these mechanisms, although a good starting point, are not truly representative of the original in vivo tumours in terms of architectural and cellular complexity $(33,34)$. The use of patient-derived xenograft models offers the benefit of more closely reproducing the human in vivo tumour microenvironment for various therapeutic testing purposes. However, the process is lengthy 


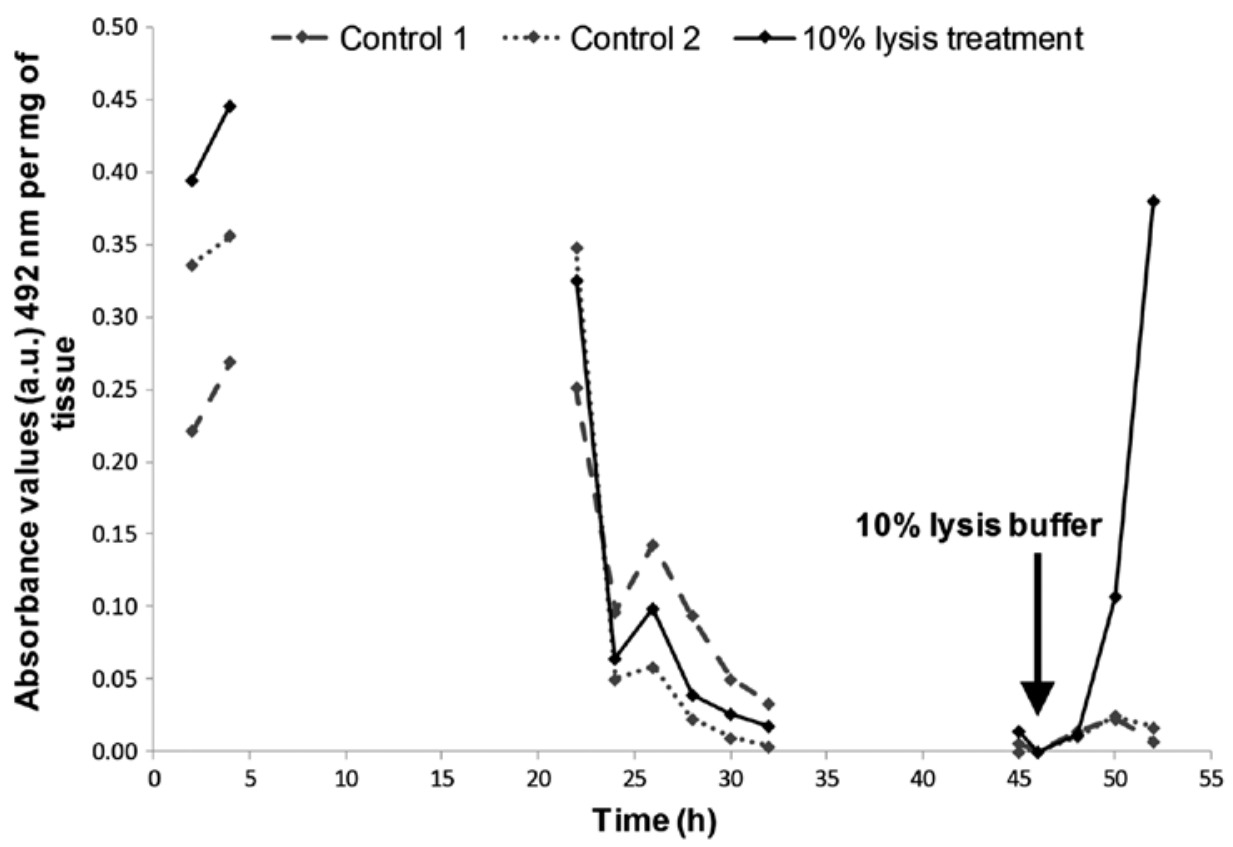

Figure 6. LDH release levels from tissue following lysis treatment in microfluidic devices. LDH release from an oral cavity floor of mouth primary tumour (PT2) following 52-h incubation in three microfluidic devices, subjected to no lysis buffer treatment $(\mathrm{n}=2)$ and addition of $10 \%$ lysis buffer $6 \mathrm{~h}$ prior to the end of the experiment $(\mathrm{n}=1)$. The absorbance values were assessed in duplicate and standardised per $\mathrm{mg}$ of tissue biopsy $(5 \mathrm{mg}$ lysis, $7.1 \mathrm{mg}$ control $1 \mathrm{and} 5.5 \mathrm{mg}$ control 2).

(xenograft generation takes up to six months), costly (tens of thousands of dollars), uses a large number of animals and the tumour is not entirely free from the rodent host influences (35-40). Microfluidic culture of 3-dimensional pieces of patient-derived tumour tissue $\left(3 \mathrm{~mm}^{3}\right)$ in a pseudo in vivo microenvironment, has the potential to overcome many, if not all, of the limitations described above (41). The continuous delivery of nutrients and removal of waste from a piece of tissue whilst maintaining complex multicellular architecture, without rodent influence, gives microfluidic technology unique characteristics to be a platform for preclinical biological investigations. The ability to run multiple samples in parallel microfluidic devices is fundamental, to ensure representative parts of the tumour are responding in the same way to the treatment supplied, if this methodology is to be transferred into the clinical setting, whereas the development of multiple xenograft models for single regimen testing is much more difficult $(37,39)$.

The present study has demonstrated the novel application of an in-house designed microfluidic device to interrogate the response of HNSCC tissues to irradiation, in terms of cell death and proliferation. Tumour perfusion and irradiation were carried out on chip, mimicking the microenvironment in vivo, whilst analysis of the markers was done either from the effluent collected during the perfusion, or using the tissue biopsies post-experiment. An initial peak of LDH release was observed at the beginning of the perfusion which is consistent with previous studies $(18,22,23)$ and is most probably a result of cell damage caused during tissue manipulation. Previous studies which have used the same microfluidic device have measured increased LDH release from tissues in response to the addition of lysis buffer (23), when oxygen was removed from the culture medium (24), and following exposure to ethanol levels $>100 \mathrm{mM}$ (22), which helps to verify the viability of tissue prior to induction of damage. Elevated LDH serum levels in patients with nasopharyngeal carcinoma have also been detected in vivo following treatment with intensitymodulated radiotherapy (42). In contrast, during the present study, the four single-dose irradiations $\leq 20$ Gy had no consistent effect in triggering necrotic cell death measured by LDH release. These results are in agreement with the results seen by Carr et al (18) who only observed a consistent increase in LDH release from HNSCC tissue following administration of the highest dose of irradiation given (40 Gy). The lack of LDH release following irradiation was not due to the fact that the tissue had all died during manipulation as the addition of lysis reagent to the tissue at the end of the microfluidic culture, post-irradiation induced a sharp increase in $\mathrm{LDH}$ release confirming the viability of the tissue (Fig. 6). It is probable that the lack of LDH is due to the relatively short timeframe over which the tissue was analysed.

Since radioresistance is multifactorial, the use of more than one marker to predict HNSCC response is essential (43). In comparison to the preliminary study previously conducted by Carr et al (18), additional markers were evaluated to measure cell death and proliferation in both non-irradiated and irradiated samples. One of the impacts of ionising radiation is the formation of DNA double-strand breaks (DSBs and the subsequent activation of the DNA-damage response (DDR) pathway. TUNEL has been extensively used to detect DNA fragmentation and later stages of apoptosis (44). An increase in the apoptotic rate following irradiation on HNSCC cells has been demonstrated previously by Feng et al (45) using TUNEL and the effect was enhanced when ataxia telangiectasia mutated (ATM), an essential component of the DNA repair pathway, was inhibited $(45,46)$. These results are in agreement with the data in the present study which showed that the apoptotic rate of the HNSCC increased following irradiation compared to the non-irradiated tissue which had a low level of DNA-strand breaks. 
The phosphorylation of the histone $\mathrm{H} 2 \mathrm{AX}(\gamma \mathrm{H} 2 \mathrm{AX})$ is one of the early events following the generation of DNA-DSBs and is responsible for the recruitment of other molecules in the DDR pathway (47). It is thought that $\gamma \mathrm{H} 2 \mathrm{AX}$ levels increase to a peak expression at $1 \mathrm{~h}$ following irradiation and return to normal within $24 \mathrm{~h}(28,48,49)$. However, a higher retention level of $\gamma \mathrm{H} 2 \mathrm{AX}$ at $24 \mathrm{~h}$ following irradiation has been observed in a radiosensitive cervical cancer cell line compared to a non-sensitive one, where the remaining $\gamma \mathrm{H} 2 \mathrm{AX}$ level correlated with the surviving fraction of cells determined using the clonogenic assay (48), suggesting impaired DNA repair, extended DNA repair and radiosensitivity $(28,48,49)$. The majority of the tumours in the current study, observed at $24 \mathrm{~h}$ post-irradiation, had a slight increase in $\gamma \mathrm{H} 2 \mathrm{AX}$ following irradiation compared with the corresponding control tissues, however, this was only significant in one of the five tissues (PT2). The increased expression of $\gamma \mathrm{H} 2 \mathrm{AX}$ seen in PT2 at $24 \mathrm{~h}$ post-irradiation may suggest that this tumour is more sensitive to irradiation, unfortunately this patient was treated with surgery alone so no clinical correlation could be made.

The presence of $\mathrm{cCK} 18$, as a marker of activation of the caspases involved in the apoptotic pathway, has been used previously to demonstrate increases in apoptosis in tumour tissue following chemotherapy treatments. Conflicting results have been reported, however, as the rectal studies showed no prognostic value for cCK18 $(50,51)$, but in the gastric/gastro-oesophageal cancer patients exposed to neoadjuvant chemotherapy $43.6 \%$ of patients that had tumours positive for cCK18, following treatment, had a favourable tumour response compared with $23.8 \%$ of patients with tumours negative for cCK18 expression (52). In the present study, a varied response to irradiation in terms of the CK18-LI was observed between HNSCC samples from different subsites. For example, the two oral cavity tumours (PT1 and PT2) showed minimal response to single-dose irradiation whereas, the laryngeal supraglottic tumour (PT3) demonstrated a dose-dependent increase following irradiation, reaching significance compared with the control at $20 \mathrm{~Gy}$; greater numbers of tumours would be needed to clarify if these differences are sub-site specific. Unexpectedly, two metastatic lymph nodes (LN1 and LN2) had a higher CK18-LI (>30\%) following 15 Gy compared with control tissues which decreased again after 20 Gy possibly due to increased cellular damage following such a high single acute dose (53). The varied responses observed among the five tumours confirmed the inter-tumour variation on the HNSCC response to irradiation and further emphasised the value for individual analysis of tumours to determine the patient specific response.

A high pre-treatment proliferation index, measured using Ki67, has been shown previously to correlate with reduced survival/increased recurrence in patients with HNSCC following irradiation $(43,54)$, however, this is the first study to use microfluidic culture to analyse the proliferation of tumour cells in response to irradiation ex vivo. As hypothesised, the expression of Ki-67 in both metastatic lymph nodes in the present study followed a trend of dose-dependent reduction after irradiation. This was in agreement with other studies which have demonstrated a reduction of Ki-67-labelling by $79 \%$ in male Wistar rat tissues that were removed from rats sacrificed 3 weeks following 10 Gy $\gamma$-irradiation (55). In addition, a reduction of the Ki-67 labelling index was observed during the first week following five fractions (1.1 Gy per fraction) per week for seven weeks on human normal skin biopsies (56). A similar dose-dependent reduction was seen in the laryngeal tumour (PT3) except in tissues with 15 Gy irradiation. The fact that $15 \mathrm{~Gy}$ irradiation appeared to have little effect in the laryngeal tumour biopsies, is likely to indicate intra-tumour heterogeneity and highlights that in future experiments a greater number of replicates need to be established for each treatment group. In contrast, no effect of irradiation on proliferation was observed in PT1 and PT2 samples, who were both treated clinically with surgery, suggesting that these tumours might not be responsive to irradiation.

In conclusion, although the authors acknowledge the microfluidic maintenance of 3-dimensional tumour biopsies has limitations, principally in the loss of vasculature, this proof-of-concept study shows the potential of the microfluidic-irradiation model and the IHC expression profiles to determine the response of an individual's tumour to irradiation and provides a system for further investigations of various treatment regimens using a methodology applicable to all solid tumours. The variation of the tumour responses detected between different HNSCC samples and when treating samples from the same patient with different irradiation doses suggests the existence of both inter- and intra-patient variation respectively in terms of response to irradiation in the microfluidic model, highlighting again the need for such a model to customise treatment on an individual patient basis prior to clinical intervention. The results show that a larger scale investigation is the priority, running multiple repeats so that the 'average' effect can be determined and correlated with the corresponding patients' clinical behaviour. A further modification to the approach being developed in our group is to use precision cut tissue slices in a redesigned tissue device which gives improved fluid flow dynamics, increasing the perfusion kinetics, ensuring optimal nutrient delivery and waste removal. Studies are ongoing comparing these two tissue-bearing devices. Prediction of response would bring multiple benefits, firstly to the patients in terms of treatment effectiveness and quality of life and secondarily to the NHS in terms of cost reduction and improved patient care.

\section{Acknowledgements}

We would like to thank Mr. J. Jose, consultant head and neck surgeon, and the rest of the surgical team at Castle Hill Hospital, Hull, United Kingdom, for providing the tissue samples; Professor A. Beavis, consultant medical physicist and head of radiation physics for the Hull and East Yorkshire Hospitals NHS Trust, Mr. C. Horsfield, senior radiotherapy physicist, and other physicists for their expertise and assistance with the irradiation treatments.

\section{References}

1. Ferlay J, Soerjomataram I, Dikshit R, Eser S, Mathers C, Rebelo M, Parkin DM, Forman D and Bray F: Cancer incidence and mortality worldwide: Sources, methods and major patterns in GLOBOCAN 2012. Int J Cancer 136: E359-E386, 2015. 
2. Grégoire V, Lefebvre JL, Licitra L and Felip E; EHNSESMO-ESTRO Guidelines Working Group: Squamous cell carcinoma of the head and neck: EHNS-ESMO-ESTRO Clinical Practice Guidelines for diagnosis, treatment and follow-up. Ann Oncol 21 (Suppl 5): V184-V186, 2010.

3. Galbiatti AL, Padovani-Junior JA, Maníglia JV, Rodrigues CD, Pavarino EC and Goloni-Bertollo EM: Head and neck cancer: Causes, prevention and treatment. Braz J Otorhinolaryngol 79: 239-247, 2013

4. The Royal College of Radiologists: Radiotherapy DoseFractionation, 2006. https://www.rcr.ac.uk/publication/ radiotherapy-dose-fractionation. Accessed December, 2013.

5. Burtness B: Moving forward in the management of squamous cell carcinoma of the head and neck: Promising immuno-oncology approaches. Am J Hematol Oncol 11: 28-31, 2015.

6. Sadraei NH, Sikora AG and Brizel DM: Immunotherapy and checkpoint inhibitors in recurrent and metastatic head and neck cancer. Am Soc Clin Oncol Educ Book 35: e277-282, 2016.

7. Head and Neck NSSG; Head and Neck Network Group: Head and Neck Cancer Treatment Guidelines. NHS, UK, 2014.

8. American Cancer Society: Cancer Facts and Figures 2015. American Cancer Society Inc., Atlanta, GA, 2015.

9. Scaife L, Hodgkinson VC, Drew PJ, Lind MJ and Cawkwell L: Differential proteomics in the search for biomarkers of radiotherapy resistance. Expert Rev Proteomics 8: 535-552, 2011.

10. Biau J, Chautard E, Miroir J and Lapeyre M: Radioresistance parameters in head and neck cancers and methods to radiosensitize. Cancer Radiother 19: 337-346, 2015.

11. Guy JB, Rancoule C, Méry B, Espenel S, Wozny AS, Simonet S, Vallard A, Alphonse G, Ardail D, Rodriguez-Lafrasse C, et al: Radiosensitivity and/or radioresistance of head and neck cancers: Biological angle. Bull Cancer 103: 41-47, 2016 (In French).

12. Ataman OU, Bentzen SM, Wilson GD, Daley FM, Richman PI, Saunders MI and Dische S: Molecular biomarkers and site of first recurrence after radiotherapy for head and neck cancer. Eur J Cancer 40: 2734-2741, 2004

13. Kumar B, Cordell KG, Lee JS, Worden FP, Prince ME, Tran HH, Wolf GT, Urba SG, Chepeha DB, Teknos TN, et al: EGFR, p16, HPV Titer, Bcl-xL and p53, sex, and smoking as indicators of response to therapy and survival in oropharyngeal cancer. J Clin Oncol 26: 3128-3137, 2008

14. Moeller BJ, Yordy JS, Williams MD, Giri U, Raju U, Molkentine DP, Byers LA, Heymach JV, Story MD, Lee JJ, et al: DNA repair biomarker profiling of head and neck cancer: Ku80 expression predicts locoregional failure and death following radiotherapy. Clin Cancer Res 17: 2035-2043, 2011.

15. Akervall J, Nandalur S, Zhang J, Qian CN, Goldstein N, Gyllerup P, Gardinger Y, Alm J, Lorenc K, Nilsson K, et al: A novel panel of biomarkers predicts radioresistance in patients with squamous cell carcinoma of the head and neck. Eur J Cancer 50: 570-581, 2014

16. Kilic S, Cracchiolo B, Gabel M, Haffty B and Mahmoud O: The relevance of molecular biomarkers in cervical cancer patients treated with radiotherapy. Ann Transl Med 3: 261, 2015.

17. Sharma A, Bode B, Wenger RH, Lehmann K, Sartori AA, Moch H, Knuth A, Boehmer L and Broek M: $\gamma$-Radiation promotes immunological recognition of cancer cells through increased expression of cancer-testis antigens in vitro and in vivo. PLoS One 6: e28217, 2011.

18. Carr SD, Green VL, Stafford ND and Greenman J: Analysis of radiation-induced cell death in head and neck squamous cell carcinoma and rat liver maintained in microfluidic devices. Otolaryngol Head Neck Surg 150: 73-80, 2014

19. Ma H, Xu H and Qin J: Biomimetic tumor microenvironment on a microfluidic platform. Biomicrofluidics 7: 11501, 2013.

20. Halldorsson S, Lucumi E, Gómez-Sjöberg R and Fleming RM: Advantages and challenges of microfluidic cell culture in polydimethylsiloxane devices. Biosens Bioelectron 63: 218-231, 2015.

21. van der Meer AD and van den Berg A: Organs-on-chips: Breaking the in vitro impasse. Integr Biol 4: 461-470, 2012.

22. Hattersley SM, Sylvester DC, Dyer CE, Stafford ND, Haswell SJ and Greenman J: A microfluidic system for testing the responses of head and neck squamous cell carcinoma tissue biopsies to treatment with chemotherapy drugs. Ann Biomed Eng 40: $1277-1288,2012$

23. Hattersley SM, Dyer CE, Greenman $\mathbf{J}$ and Haswell SJ Development of a microfluidic device for the maintenance and interrogation of viable tissue biopsies. Lab Chip 8: 1842-1846, 2008 .
24. Cheah LT, Dou YH, Seymour AM, Dyer CE, Haswell SJ, Wadhawan JD and Greenman J: Microfluidic perfusion system for maintaining viable heart tissue with real-time electrochemical monitoring of reactive oxygen species. Lab Chip 10: 2720-2726, 2010.

25. Hakem R: DNA-damage repair; the good, the bad, and the ugly. EMBO J 27: 589-605, 2008.

26. Mahaney BL, Meek K and Lees-Miller SP: Repair of ionizing radiation-induced DNA double-strand breaks by non-homologous end-joining. Biochem J 417: 639-650, 2009.

27. Willers H, Azzoli CG, Santivasi WL and Xia F: Basic mechanisms of therapeutic resistance to radiation and chemotherapy in lung cancer. Cancer J 19: 200-207, 2013.

28. Olive PL and Banáth JP: Kinetics of $\mathrm{H} 2 \mathrm{AX}$ phosphorylation after exposure to cisplatin. Cytometry B Clin Cytom 76: 79-90, 2009

29. Taneja N, Davis M, Choy JS, Beckett MA, Singh R, Kron SJ and Weichselbaum RR: Histone H2AX phosphorylation as a predictor of radiosensitivity and target for radiotherapy. J Biol Chem 279: 2273-2280, 2004

30. McCreedy T and Wilson NG: Microfabricated reactors for on-chip heterogeneous catalysis. Analyst (Lond) 126: 21-23, 2001.

31. Astolfi M, Péant B, Lateef MA, Rousset N, Kendall-Dupont J, Carmona E, Monet F, Saad F, Provencher D, Mes-Masson AM, et al: Micro-dissected tumor tissues on chip: An ex vivo method for drug testing and personalized therapy. Lab Chip 16: 312-325, 2016.

32. Loo DT: TUNEL assay. An overview of techniques. Methods Mol Biol 203: 21-30, 2002.

33. Richmond A and Su Y: Mouse xenograft models vs GEM models for human cancer therapeutics. Dis Model Mech 1: 78-82, 2008.

34. Stein AP, Swick AD, Smith MA, Blitzer GC, Yang RZ, Saha S, Harari PM, Lambert PF, Liu CZ and Kimple RJ: Xenograft assessment of predictive biomarkers for standard head and neck cancer therapies. Cancer Med 4: 699-712, 2015.

35. Yang J, Liu A, Dougherty C, Chen X, Guzman R and Nandi S: Beware of contaminating mouse cells in human xenografts from nude mice. Anticancer Res 20A: 1635-1639, 2000.

36. Garrido-Laguna I, Uson M, Rajeshkumar NV, Tan AC, de Oliveira E, Karikari C, Villaroel MC, Salomon A, Taylor G, Sharma R, et al: Tumor engraftment in nude mice and enrichment in stroma- related gene pathways predict poor survival and resistance to gemcitabine in patients with pancreatic cancer. Clin Cancer Res 17: 5793-5800, 2011

37. Kahn J, Tofilon PJ and Camphausen K: Preclinical models in radiation oncology. Radiat Oncol 7: 223, 2012.

38. Kimple RJ, Harari PM, Torres AD, Yang RZ, Soriano BJ, Yu M, Armstrong EA, Blitzer GC, Smith MA, Lorenz LD, et al: Development and characterization of HPV-positive and HPV-negative head and neck squamous cell carcinoma tumorgrafts. Clin Cancer Res 19: 855-864, 2013.

39. Malaney P, Nicosia SV and Davé V: One mouse, one patient paradigm: New avatars of personalized cancer therapy. Cancer Lett 344: 1-12, 2014

40. Stebbing J, Paz K, Schwartz GK, Wexler LH, Maki R, Pollock RE, Morris R, Cohen R, Shankar A, Blackman G, et al: Patient-derived xenografts for individualized care in advanced sarcoma. Cancer 120: 2006-2015, 2014.

41. Dawson AL, Green VL, Bower R and Greenman J: Microfluidics: The fur-free way towards personalised medicine in cancer therapy. Univ Hull 3: 12-17, 2016

42. Zhou GQ, Ren XY, Mao YP, Chen L, Sun Y, Liu LZ, Li L, Lin AH, Mai HQ and Ma J: Prognostic implications of dynamic serum lactate dehydrogenase assessments in nasopharyngeal carcinoma patients treated with intensity-modulated radiotherapy. Sci Rep 6: 22326,2016

43. Raybaud H, Fortin A, Bairati I, Morency R, Monteil RA and Têtu B: Nuclear DNA content, an adjunct to p53 and Ki-67 as a marker of resistance to radiation therapy in oral cavity and pharyngeal squamous cell carcinoma. Int J Oral Maxillofac Surg 29: 36-41, 2000.

44. Sundquist T, Moravec R, Niles A, O'Brien M and Riss T: Timing your apoptosis assays. Cell Notes 16: 18-21, 2006.

45. Feng J, Zou J, Li L, Zhao Y and Liu S: Antisense oligodeoxynucleotides targeting ATM strengthen apoptosis of laryngeal squamous cell carcinoma grown in nude mice. J Exp Clin Cancer Res 30: 43, 2011.

46. Zou J, Qiao X, Ye H, Yang Y, Zheng X, Zhao H and Liu S: Antisense inhibition of ATM gene enhances the radiosensitivity of head and neck squamous cell carcinoma in mice. J Exp Clin Cancer Res 27: 56, 2008. 
47. Valdiglesias V, Giunta S, Fenech M, Neri M and Bonassi S: $\gamma \mathrm{H} 2 \mathrm{AX}$ as a marker of DNA double-strand breaks and genomic instability in human population studies. Mutat Res 753: 24-40, 2013.

48. Banáth JP, Macphail SH and Olive PL: Radiation sensitivity, $\mathrm{H} 2 \mathrm{AX}$ phosphorylation, and kinetics of repair of DNA strand breaks in irradiated cervical cancer cell lines. Cancer Res 64: 7144-7149, 2004.

49. Clingen PH, Wu JY, Miller J, Mistry N, Chin F, Wynne P, Prise KM and Hartley JA: Histone H2AX phosphorylation as a molecular pharmacological marker for DNA interstrand crosslink cancer chemotherapy. Biochem Pharmacol 76: 19-27, 2008.

50. Debucquoy A, Goethals L, Libbrecht L, Perneel C, Geboes K, Ectors N, McBride WH and Haustermans K: Molecular and clinico-pathological markers in rectal cancer: A tissue microarray study. Int J Colorectal Dis 24: 129-138, 2009.

51. Debucquoy A, Libbrecht L, Roobrouck V, Goethals L, McBride W and Haustermans K: Morphological features and molecular markers in rectal cancer from 95 patients included in the European Organisation for Research and Treatment of Cancer 22921 trial: Prognostic value and effects of preoperative radio (chemo) therapy. Eur J Cancer 44: 791-797, 2008.
52. Fareed KR, Soomro IN, Hameed K, Arora A, Lobo DN, Parsons SL and Madhusudan S: Caspase-cleaved cytokeratin-18 and tumour regression in gastro-oesophageal adenocarcinomas treated with neoadjuvant chemotherapy. World J Gastroenterol 18: 1915-1920, 2012.

53. Koukourakis MI: Radiation damage and radioprotectants: New concepts in the era of molecular medicine. Br J Radiol 85: 313-330, 2012.

54. Buffa FM, Bentzen SM, Daley FM, Dische S, Saunders MI, Richman PI and Wilson GD: Molecular marker profiles predict locoregional control of head and neck squamous cell carcinoma in a randomized trial of continuous hyperfractionated accelerated radiotherapy. Clin Cancer Res 10: 3745-3754, 2004.

55. Kee N, Sivalingam S, Boonstra R and Wojtowicz JM: The utility of $\mathrm{Ki}-67$ and BrdU as proliferative markers of adult neurogenesis. J Neurosci Methods 115: 97-105, 2002.

56. Turesson I, Bernefors R, Book M, Flogegård M, Hermansson I, Johansson KA, Lindh A, Sigurdardottir S, Thunberg U and Nyman J: Normal tissue response to low doses of radiotherapy assessed by molecular markers - a study of skin in patients treated for prostate cancer. Acta Oncol 40: 941-951, 2001. 